\title{
ENTRE PONTOS E NÓS: A PRODUÇÃO CIENTÍFICA SOBRE EDUCAÇÃO ESPECIAL NO CURSO DE PEDAGOGIA DA UVA-SOBRAL-CE
}

\author{
ENTRE PUNTOS E AMARRAS: LA PRODUCIÓN CIENTÍFICA ACERCA DE LA \\ EDUCACIÓN ESPECIAL EM EL CURSO DE PEDAGOGÍA DE LA UVA-SOBRAL- \\ $C E$
}

\section{BETWEEN POINTS AND RIGHTS GUARDED: THE SCIENTIFIC PRODUCTION SPECIAL EDUCACTION IN THE UVA-SOBRAL-CE PEDAGOGY COURSE}

\author{
Wildiane Gonçalves do NASCIMENTO \\ Railane Bento VIEIRA. \\ Rejane Maria Gomes da SILVA, \\ Ana Cristina Silva $\mathrm{SOARES}_{4}$ \\ Francisco Ricardo Miranda $\mathrm{PINTO}_{5}$
}

RESUMO: A temática central deste é a Educação Especial enquanto possibilidade de assegurar os direitos que velam os documentos oficiais. Tem como objetivo geral explorar a produção científica do curso de Pedagogia da Universidade Estadual Vale do Acaraú sobre a Educação Especial e a área em estudo. A literatura contemplada busca contextualizar o surgimento da Educação Especial a partir de Capellini; Mendes (2005), Rosseto; Tureck (2005); Bruno (2006), dando ênfase no contexto e nos discursos sobre a Educação Especial nos Documentos Oficiais a partir de Brasil (1994), UNESCO (1990), Brasil (1996), Brasil (2012), Brasil (2015), dentre outros. Trata-se de estudo de abordagem qualitativa, do tipo revisão de literatura integrativa realizada no Curso de Pedagogia da Universidade Estadual Vale do Acaraú - UVA tendo como lócus o Grupo de Pesquisa História e Memória Social da Educação e da Cultura (MEDUC) com a análise de dezessete artigos do acervo daquele grupo. Os resultados cruzados demonstram o quão complexo e importante se faz abordar esse tema entre profissionais da área ao passo que se concluiu que crianças com deficiência estão entre "pontos e nós", pois mesmo com a existência das leis que lhes propiciam direitos de inclusão, ainda há exclusão velada no meio em que estão inseridas.

PALAVRAS-CHAVE: Educação especial. Produção científica. Pedagogia.

1 Universidade Estadual Vale do Acaraú (UVA), Sobral - CE - Brasil. Pedagoga. E-mail: wildianee@outlook.com.

${ }^{2}$ Universidade Estadual Vale do Acaraú (UVA), Sobral - CE - Brasil. Profa. Dra. Do Curso de Pedagogia. E-mail: rejanemgs@gmail.com.

${ }^{3}$ Universidade Estadual Vale do Acaraú (UVA), Sobral - CE - Brasil. Docente do Curso de Pedagogia. Doutora em Educação. E-mail: rejanemgs@gmail.com.

${ }^{4}$ Universidade Estadual Vale do Acaraú (UVA), Sobral - CE - Brasil. Prof. Me. em Saúde Coletiva. Docente do Curso de Pedagogia. E-mail: ricardomiranda195@gmail.com. 
RESUMEN: Este estudio se centra en la Educación Especial como una posibilidad para asegurar los derechos protegidos por los documentos oficiales. Su objetivo es explorar la producción científica del curso de Pedagogía de la Universidad Estatal de Vale do Acaraú sobre la Educación Especial y el área de estudio. La literatura contemplada busca contextualizar el surgimiento de la Educación Especial de los teóricos Capellini; Mendes (2005), Rosseto; Tureck (2005) y Bruno (2006), enfatizando el contexto y discursos sobre Educación Especial en los Documentos Oficiales apoyados por Brasil (1994), UNESCO (1990), Brasil (1996), Brasil (2012), Brasil (2015), entre otros. Este estudio se realizó mediante un enfoque cualitativo, utilizando una revisión de la literatura integradora realizada en el curso de Pedagogía de la mencionada universidad y tuvo como locus el grupo de investigación História y Memoria Social de la Cultura y Cultura (MEDUC), en el que diecisiete artículos De esta colección de grupo. Los resultados muestran la complejidad e importancia de la discusión de este tema entre los profesionales de este campo, concluyendo que aún con la existencia de leyes que otorgan derechos de inclusión, los niños con discapacidad siguen siendo excluidos en su propio entorno.

PALABRAS CLAVES: Educación especial. Producción cientifica. Pedagogía.

ABSTRACT: This study focuses on Special Education as a possibility to ensure the rights guarded by the official documents. It is aimed to explore the scientific production of the Pedagogy course from the State University of Vale do Acaraú concerning the Special Education and the study area. The contemplated literature seeks to contextualize the emergence of Special Education from the theorists Capellini; Mendes (2005), Rosseto; Tureck (2005) and Bruno (2006), emphasizing the context and discourses on Special Education in the Official Documents supported by Brasil (1994), UNESCO (1990), Brasil (1996), Brasil (2012), Brasil (2015), among others. This study was carried out by means of a qualitative approach, using an integrative literature review conducted in the Pedagogy course of the aforesaid university and had the research group História e Memória Social da Educação e da Cultura (MEDUC) as locus, in which seventeen articles of this group collection were analyzed. The results show the complexity and importance in discussing this issue among professionals of this field, while it was concluded that even with the existence of laws providing rights of inclusion, children with disabilities are still being excluded in their own environment.

KEYWORDS: Special education. Scientific production. Pedagogy.

\section{Introdução}

A Educação Especial (EE) é uma das modalidades educacionais que prima pela equidade em oportunidades educacionais e direito à dignidade humana. A temática surge por inquietação e curiosidade em identificar o espaço ocupado pela Educação Especial na formação dos acadêmicos do Curso de Pedagogia da Universidade Vale do Acaraú (UVA) 
e como ela se traduz na produção científica falando sobre esse assunto, visto sua frágil abordagem no decorrer da graduação, que quando estudada, é de forma superficial.

Faz-se relevante para profissionais da educação que, de posse do conhecimento científico, poderão pesquisar, intervir, interagir e contribuir na prática de inclusão de maneira mais eficaz, livres de preconceitos; e para a sociedade em si, na perspectiva de que conhecendo mais sobre a Educação Especial e os direitos que as leis asseguram, se cogita a redução do preconceito e da indiferença, pela sociedade, com os deficientes. Espera-se contribuir à comunidade acadêmica, sociedade e professores, levando ao conhecimento de todos como a universidade tem abordado a temática na formação acadêmica e que espaço tem ocupado na produção científica.

O ponto de partida foram as perguntas-problemas: Qual contexto dessa modalidade educacional e o que os documentos oficiais falam sobre essa educação? Como e/ou se ocorre a integração e inclusão das crianças especiais nas escolas? Quais as principais dificuldades encontradas? Com base nesses questionamentos, este trabalho busca subsídios dentro do contexto de Educação Inclusiva.

O objetivo geral é analisar o espaço ocupado pela temática Educação Especial na produção científica do Curso de Pedagogia da Universidade Estadual Vale do Acaraú.

A Revisão de Literatura aborda a contextualização da Educação Inclusiva a partir de Capellini e Mendes (2005), Rodrigues (2008), Guhur (2012) entre outros. O segundo tópico fará o resgate sobre a Educação Inclusiva nos Documentos Oficiais a partir da Lei de Diretrizes e Bases da Educação Nacional (BRASIL, 1996), Declaração de Salamanca (UNESCO, 1990), Constituição de 1988 (BRASIL, 1988) e outros.

Estudo de abordagem qualitativa, do tipo revisão integrativa, realizado no Curso de Pedagogia da Universidade Estadual Vale do Acaraú, Sobral-Ceará, tendo como lócus o Grupo de Pesquisa História e Memória Social da Educação e da Cultura (MEDUC). Utilizou-se como um dos critérios de inclusão o recorte temporal dos últimos cinco anos, de 2012 a 2016, e como exclusão, os artigos que com títulos voltados à Educação Especial e/ou Educação Inclusiva não contemplasse o assunto. Foram selecionados 36 (trinta e seis) artigos, após filtragem dos critérios sobraram 17 (dezessete).

Os resultados apontam frágil produção científica voltada para à temática em questão, sobremaneira pelo tempo de existência da universidade e do curso de Pedagogia o que pode denotar fragilidade no interesse de pesquisadores e acadêmicos sobre o reconhecimento dos direitos adquiridos de forma lenta e as lacunas na formação dos 
futuros profissionais que ao adentrarem o mercado de trabalho terão, em suas demandas, contato com a necessidade da Educação Especial.

\section{Contextualizando a Educação Especial da Europa ao Brasil}

A Educação Especial é uma modalidade de ensino da Educação voltada ao grupo de pessoas com deficiências, sejam essas física, sensorial ou cognitiva e altas habilidades e/ou superdotação, assegurando ensino de qualidade, respeito e igualdade, com o propósito de prepará-los para a vida, oferecendo as mesmas condições de inserção social sem discriminação. Ainda gera polêmica, haja vistas ainda coexistir o desconhecimento que gera preconceito e discriminação de forma que "a Educação Especial tem sido uma área fértil para o aparecimento de polêmicas, propostas inovadoras e modismos, seus conceitos têm provocado discussões e debates desde a terminologia adotada, às formas e aos meios de efetivação das suas práticas." (ROSSETTO; TURECK, 2005, p. 1).

Até o século XVIII a inclusão de pessoas com deficiência era inexistente, elas eram consideradas inválidas e incapazes (MENDES, 1995). No Brasil, remota ao século XIX, com a criação do Instituto Benjamim Constant - IBC e em 1957 o Instituto Nacional de Educação de Surdos.

No fim do século XVIII Philippe Pinel, renomado médico, avaliou o caso de Victor de Aveyron, encontrado na floresta e concluiu não haver nenhuma esperança em educá-lo. Jean-Marc-Gaspard Itard tratou o menino e defendeu a reintegração daquele à sociedade, iniciando, assim, as tentativas de educar crianças com deficiências (MARFINATI , 2012; BRUNO, 2006), momento em que se "[...] descobriu um novo objeto para a medicina: as psicoses infantis" (PÓSTEL; QUÉTEL, 1987, p. 507).

No século XIX as pessoas com deficiências viviam o abandono socioeducacional, e durante a Idade Média eram considerados seres possuídos pelo demônio, incapazes de exercer o sacerdócio, segundo a igreja e/ou "[...] sobrevivia na família, escapando à exposição, sendo abandonadas ou servindo de palhaços em atrações.”. (RODRIGUES, 2008, p. 8).

No Brasil, neste período, cria-se duas instituições com inspiração da experiência europeia, a primeira o Instituto dos Meninos Cegos, em 1854, sob a direção de Benjamin Constant, e a segunda, o Instituto dos Surdos-Mudos, em 1857, sob a direção do mestre francês Edouard Huet, ambas localizadas no Rio de Janeiro (JANNUZZI, 1992; 2004; 
MAZZOTTA, 2005). Segundo Jannuzzi (1992) e Mazzotta (2005) em 1874, na Bahia, cria-se o Hospital Juliano Moreira, dando início a assistência médica às pessoas com deficiência intelectual. Em 1887, no Rio de Janeiro, surge a "Escola México" para o atendimento de pessoas com deficiências físicas e intelectuais.

Deste modo no século XX surgiram as primeiras experiências educacionais em instituições que assistiam pessoas com deficiência intelectual, dentre elas estão a Sociedade Pestalozzi (1932), Fazenda do Rosário (1954) e Associação de Pais e Amigos dos Excepcionais (APAE) (1954). A partir de 1958 o Ministério da Educação prestou assistência financeira às secretarias de educação e instituições especializadas, assim o atendimento nessas instituições existiu por muito tempo em paralelo ao ensino regular (GUHUR, 2012).

A Política Brasileira de Educação Especial, nos anos noventa, enfatizou os avanços em termos da legislação e mesmo da compreensão sobre o significado das Necessidades Educacionais Especiais (NEE) e das políticas educacionais.

\section{Discurso sobre a Educação Especial nos documentos oficiais}

Os documentos oficiais que criam políticas de atendimento às pessoas com deficiências têm seu apogeu em 1948 com a Declaração Universal dos Direitos Humanos que assegura a todas as pessoas o direito à liberdade, vida digna e educação fundamental para o desenvolvimento social. Em 1990, foi celebrada a Declaração de Jomtien que determina o fim de estereótipos e de preconceitos de qualquer natureza na Educação, reconhecendo-a como um direito de todos.

Já em 1994 foi elaborada, na Espanha, a Declaração de Salamanca, que objetivava a ocupação dos mesmos espaços sociais e a garantia de acesso à bens históricos e culturais da sociedade, independentemente das necessidades especiais e diferenças existentes, sejam elas de gêneros, culturais ou étnicas. Ressalta a necessidade de uma pedagogia e práticas pedagógicas com foco na diversidade, necessidade de cada aluno (BRASIL, 1994).

A Convenção da Guatemala (1999) elimina todas as formas de discriminação contra pessoas com deficiências reafirmando os direitos e liberdades para que estas vivam de forma humana (BRASIL, 2010), foi o primeiro documento que abordou a questão da discriminação e o preconceito. O Decreto $n^{\circ}$ 3956/01 cria a Convenção Interamericana para a Eliminação de Todas as Formas de Discriminação contra as Pessoas Portadoras de 
Deficiência, reafirma os direitos anteriores aos deficientes, inclusive não serem submetidas à discriminação com base na deficiência.

No cenário brasileiro, as leis seguiram os encaminhamentos apontados pelas declarações internacionais. Na Lei № 4024/61, primeira Lei de Diretrizes e Bases (LDB), há a presença da educação de excepcionais. Em 1962 foi criada a Lei no 4169 que oficializa as convenções Braille para uso na escrita e leitura dos cegos e o Código de Contrações e Abreviaturas Braille.

Na década de 70, a Lei 5692/71, segunda LDB, englobou os alunos com deficiências físicas ou mentais, com atrasos quanto à idade regular de matrícula e os superdotados na Educação Especial. O Decreto 72425/73 criou o Centro Nacional de Educação Especial (CENESP), primeiro órgão específico à Educação Especial a nível federal e junto, a execução de cursos de formação de professores na área (BRASIL, 2010).

Em 1988, a Constituição Federal implantou uma nova prática educativa com a descentralização do poder. O Estatuto da Criança e do Adolescente (1990) responsabiliza a família, sociedade e Estado à função de assegurar às crianças e aos adolescentes o direito à vida, saúde, lazer, enfim, à dignidade em todos os sentidos (BRASIL, 2010). Já na década de 90 a Lei $n^{\circ}$ 8160/91 dispõe sobre a caracterização de símbolo que permita a identificação de pessoas portadoras de deficiência auditiva.

A LDB 9394/96, a versão em vigor, nos Artigos 58 e 59 ratificam que o Atendimento Educacional será “[...] feito em classes, escolas, ou serviços especializados [...].” (BRASIL, 2016, p.19), sempre voltados para as especificidades dos alunos, se não conseguirem isso nas classes comuns do ensino regular, novos espaços alternativos devem criados para atender adequadamente essas crianças.

A Política Nacional para a Integração da Pessoa Portadora de Deficiência (1999) ${ }^{2}$ estabeleceu a oferta gratuita e obrigatória da educação especial em redes públicas de ensino. Já as Diretrizes Nacionais para a Educação Especial na Educação Básica (2001) estabeleceram normativas nas quais o país se comprometia a adaptar e/ou construir estruturas educacionais inclusivas para melhor atender a enorme e diversa demanda de seus alunos (BRASIL, 2001).

O século XXI tem, em 2005, a criação do Decreto nº 5626/05 que regulamenta a Lei 10436/2002, visando à inclusão dos alunos surdos, da disciplina curricular de Libras, instrutor e tradutor/intérprete de Libras, Língua Portuguesa como Segunda Língua e a

${ }^{2}$ Título conforme consta no documento oficial 
organização da educação bilíngue no ensino regular, com ênfase na melhoria da educação inclusiva.

Em 2006, a Organização das Nações Unidas (ONU) aprova a Convenção Internacional sobre os direitos das Pessoas com Deficiência, um avanço histórico por situar a deficiência definitivamente no plano dos direitos humanos. Em 2007 foi lançado o Plano de Desenvolvimento da Educação (PDE) que teve como eixo a formação voltada para professores da educação especial (BRASIL, 2010).

Em 2008 foi aprovada a Política Nacional da Educação Especial na Perspectiva da Educação Inclusiva que conceitua a educação especial e define o público que ela abrangerá. Também especifica os seguintes objetivos: assegura a inclusão escolar de alunos com deficiência, transtornos globais de desenvolvimento e altas habilidades/superdotação; orienta os sistemas de ensino para garantir o acesso de todos os alunos ao ensino regular (como participação, aprendizagem e continuidade nos níveis mais elevados de ensino; oferecimento do AEE; formação professores para o AEE e demais professores para a inclusão; provimento de acessibilidade arquitetônica, nos transportes, nos mobiliários, comunicações e informação; estimulação da participação da família e da comunidade; e provimento da articulação intersetorial na implementação das políticas públicas educacionais (BRASIL, 2008).

No mesmo ano de implantação da política houve o Decreto 6571/08 que dispunha sobre o atendimento educacional especializado financiado pelo Fundo de Manutenção e Desenvolvimento da Educação Básica e da Valorização de Profissionais da Educação (FUNDEB) (BRASIL, 2008).

Em 2009, a Resolução nº 04/2009 do Conselho Nacional de Educação instituiu as Diretrizes para o Atendimento Educacional Especializado na Educação Básica e no Atendimento Educacional Especializado (AEE). Ainda no mesmo ano o Decreto $\mathrm{n}^{\circ}$ 6.949/07 que promulga a Convenção Internacional sobre os Direitos das Pessoas com Deficiência e seu Protocolo Facultativo, assinados em Nova York.

A Lei $N^{\circ} 12764 / 12$, chamada de Lei Berenice Piana fez valer os direitos da pessoa com Transtorno do Espectro Autista. A Lei Brasileira de Inclusão da Pessoa com Deficiência Lei $N^{\circ}$ 13146/15 afirma o direito universal, equitativo, sem discriminação, identificando como vulneráveis os infantes, os adolescentes, mulheres e idosos com deficiência, reafirmando a obrigação do Estado e o dever da família em educar com qualidade aos deficientes, resguardando-os de violência de quaisquer formas. 


\section{Caminhos metodológicos}

O estudo é de abordagem qualitativa, utiliza uma metodologia não estruturada baseada em pequenas amostras que proporcionem a compreensão do problema em questão (MALHOTA, 2006). O tipo de pesquisa é revisão de literatura integrativa, permite o estudo amplo de estudos do tipo experimentais e/ou não experimentais, simultâneos (SOUZA; SILVA; CARVALHO, 2010).

O universo da pesquisa é o Curso de Pedagogia da Universidade Estadual Vale do Acaraú, localizado no campus Betânia enquanto o lócus foi o Grupo de Estudos e Pesquisas História e Memorial Social da Educação e Cultura que faz parte do Centro de Filosofia, Letras e Educação.

Foram obedecidas as seis etapas definidas por Mendes, Silveira e Galvão (2008): $1^{\text {a }}$ definição do tema e seleção da hipótese; $2^{a}$ definição dos critérios de inclusão e de exclusão; $3^{\text {a }}$ etapa categorização das informações a serem extraídas; $4^{\text {a }}$ etapa: avaliação dos estudos; $5^{\mathrm{a}}$ etapa a interpretação dos resultados e $6^{\mathrm{a}}$ etapa a síntese do conhecimento.

Utilizou-se como critério de inclusão o recorte temporal dos últimos cinco anos, de 2012 a 2016, que estivessem disponíveis fisicamente para pesquisa e análise e fossem voltados à Educação Especial e/ou Educação Inclusiva. Como critério de exclusão adotouse os artigos que mesmo com seus títulos voltados à Educação Especial e/ou Educação Inclusiva não contemplasse o assunto de forma direta.

Foram identificados 36 artigos, 13 estavam fora do recorte temporal, 6 não foram encontrados fisicamente, ficando assim 17 representados ao longo dos resultados e análises por meio de quadros e tabelas indicados como A1, A2..., A17. A análise dos dados dá-se utilizando a Estatística Descritiva Simples com auxílio do Microsoft Excel.

\section{Resultados e análise de dados}

No quadro 1 são apresentados em cronologia temporal crescente, 2012-2106, o resultado da busca no MEDUC. 
Quadro 1: Produção Científica Sobre Educação Especial - Pedagogia UVA

\begin{tabular}{|l|l|l|l|l|l|l|}
\hline $\mathbf{N}^{\mathbf{0}}$ & Ano & Autor(es) & \multicolumn{1}{c|}{ Título } & \multicolumn{1}{c|}{ Objetivo } & Metodologia & \multicolumn{1}{c|}{ Resultadonto } \\
\hline $\mathbf{1}$ & 2012 & $\begin{array}{l}\text { Figueiredo; } \\
\text { Sousa }\end{array}$ & $\begin{array}{l}\text { Transtorno de } \\
\text { Déficit de } \\
\text { Atenção e } \\
\text { Hiperatividade- } \\
\text { TDAH: Desafio } \\
\text { permanente para } \\
\text { educadores }\end{array}$ & $\begin{array}{l}\text { Analisar a } \\
\text { compreensão do } \\
\text { TDAH dos } \\
\text { educadores de } \\
\text { uma escola } \\
\text { particular } \\
\text { localizada no } \\
\text { município de } \\
\text { Sobral-CE. }\end{array}$ & $\begin{array}{l}\text { Abordagem } \\
\text { qualitativa; } \\
\text { Descritiva; } \\
\text { Estudo de } \\
\text { Caso. }\end{array}$ & $\begin{array}{l}\text { Apesar da pouca } \\
\text { experiência com } \\
\text { crianças com TDAH, } \\
\text { os professores } \\
\text { conseguiram adaptar a } \\
\text { sua metodologia } \\
\text { independentemente da } \\
\text { do sistema }\end{array}$ \\
\hline $\mathbf{2}$ & 2012 & Silva; & Educação & Perceber as & Abordagem & Há grande \\
\hline
\end{tabular}

\begin{tabular}{|c|c|c|c|c|c|c|}
\hline & & & & & & (continua) \\
\hline & 2012 & Lopes & $\begin{array}{l}\text { inclusiva: a } \\
\text { inclusão dos } \\
\text { surdos no } \\
\text { ensino } \\
\text { regular }\end{array}$ & $\begin{array}{l}\text { possibilidades de } \\
\text { incluir pessoas } \\
\text { surdas no meio } \\
\text { escolar } \\
\text { junto aos alunos } \\
\text { ouvintes. }\end{array}$ & $\begin{array}{l}\text { Qualitativa; } \\
\text { Descritiva; } \\
\text { Entrevista. }\end{array}$ & $\begin{array}{l}\text { necessidade de } \\
\text { parcerias para que os } \\
\text { alunos surdos } \\
\text { encontrem nas aulas } \\
\text { condições favoráveis, } \\
\text { aprendizagem } \\
\text { qualitativa. }\end{array}$ \\
\hline 3 & 2013 & $\begin{array}{l}\text { Almeida; } \\
\text { Lopes }\end{array}$ & $\begin{array}{l}\text { A formação do } \\
\text { professor na } \\
\text { educação } \\
\text { especial. }\end{array}$ & $\begin{array}{l}\text { Compreender como } \\
\text { é feita a formação } \\
\text { dos } \\
\text { professores em } \\
\text { relação à educação } \\
\text { especial } \\
\text { nas escolas de } \\
\text { ensino regular. }\end{array}$ & Bibliográfica & $\begin{array}{l}\text { Há necessidade de } \\
\text { investimentos e } \\
\text { estudos nas áreas da } \\
\text { educação e das } \\
\text { políticas públicas. }\end{array}$ \\
\hline 4 & 2013 & $\begin{array}{l}\text { Carvalho; } \\
\text { Silva }\end{array}$ & $\begin{array}{l}\text { Escola e } \\
\text { necessidades } \\
\text { educativas } \\
\text { especiais - } \\
\text { NEE }\end{array}$ & $\begin{array}{l}\text { Objetiva registrar e } \\
\text { refletir sobre a } \\
\text { temática - } \\
\text { Necessidades } \\
\text { Educativas } \\
\text { Especiais } \\
\text { (NEE) em uma } \\
\text { escola municipal. }\end{array}$ & $\begin{array}{l}\text { Qualitativa, } \\
\text { exploratória } \\
\text { com } \\
\text { observações } \\
\text { participantes, } \\
\text { questionários } \\
\text { abertos. }\end{array}$ & $\begin{array}{l}\text { As NEE são vistas } \\
\text { como necessárias, } \\
\text { mas nesta escola o } \\
\text { que há são } \\
\text { tentativas de incluí- } \\
\text { los, porém não há } \\
\text { ferramentas nem } \\
\text { estrutura adequada. }\end{array}$ \\
\hline 5 & 2013 & $\begin{array}{l}\text { Magalhãe } \\
\text { s; } \\
\text { Nascime } \\
\text { nto }\end{array}$ & $\begin{array}{l}\text { Práticas } \\
\text { avaliativas na } \\
\text { perspectiva da } \\
\text { aprendizagem } \\
\text { no processo de } \\
\text { educação } \\
\text { inclusiva }\end{array}$ & $\begin{array}{l}\text { Conhecer e analisar } \\
\text { as práticas } \\
\text { avaliativas na } \\
\text { perspectiva da } \\
\text { inclusão } \\
\text { de crianças } \\
\text { portadoras de } \\
\text { necessidades } \\
\text { especiais do Ensino } \\
\text { Fundamental de } \\
\text { escolas públicas no } \\
\text { município de Santa } \\
\text { Quitéria-CE. }\end{array}$ & $\begin{array}{l}\text { Exploratória; } \\
\text { Qualitativa; } \\
\text { Observações; } \\
\text { Aplicação de } \\
\text { questionário. }\end{array}$ & $\begin{array}{l}\text { A forma atual de } \\
\text { avaliação de } \\
\text { aprendizagem não } \\
\text { condiz com os } \\
\text { objetivos de ensino } \\
\text { inclusivo e não } \\
\text { contempla } \\
\text { adequadamente as } \\
\text { crianças com } \\
\text { deficiências. }\end{array}$ \\
\hline 6 & 2013 & $\begin{array}{l}\text { Lopes;Ta } \\
\text { bosa }\end{array}$ & $\begin{array}{l}\text { Breves } \\
\text { reflexões } \\
\text { teóricas sobre } \\
\text { educação de } \\
\text { pessoas com } \\
\text { necessidades } \\
\end{array}$ & $\begin{array}{l}\text { Refletir à luz de } \\
\text { alguns teóricos } \\
\text { sobre a educação de } \\
\text { alunos com } \\
\text { necessidades } \\
\text { educacionais }\end{array}$ & $\begin{array}{l}\text { Bibliográfica; } \\
\text { Qualitativa. }\end{array}$ & $\begin{array}{l}\text { Ao professor, } \\
\text { considerado mediador } \\
\text { do conhecimento, } \\
\text { cabe a obrigação de } \\
\text { estar sempre } \\
\text { capacitado e }\end{array}$ \\
\hline
\end{tabular}




\begin{tabular}{|l|l|l|l|l|l|l|}
\hline & & $\begin{array}{l}\text { educacionais } \\
\text { especiais }\end{array}$ & $\begin{array}{l}\text { especiais, } \\
\text { enfatizando a } \\
\text { formação de } \\
\text { profissionais para } \\
\text { lidar com essas } \\
\text { pessoas. }\end{array}$ & $\begin{array}{l}\text { preocupado com } \\
\text { quem aprende, como } \\
\text { aprende e se aprende. }\end{array}$ \\
\hline $\mathbf{7}$ & 2013 & $\begin{array}{l}\text { Bezerra } \\
\text { Oliveira }\end{array}$ & $\begin{array}{l}\text { O Surdo cego } \\
\text { Na Sociedade: }\end{array}$ & $\begin{array}{l}\text { Analisar os desafios } \\
\text { encontrados por }\end{array}$ & $\begin{array}{l}\text { Qualitativa; } \\
\text { Estudo de } \\
\text { Caso; }\end{array}$ & $\begin{array}{l}\text { As pessoas com surdo } \\
\text { cegueira enfrentam }\end{array}$ \\
\hline
\end{tabular}

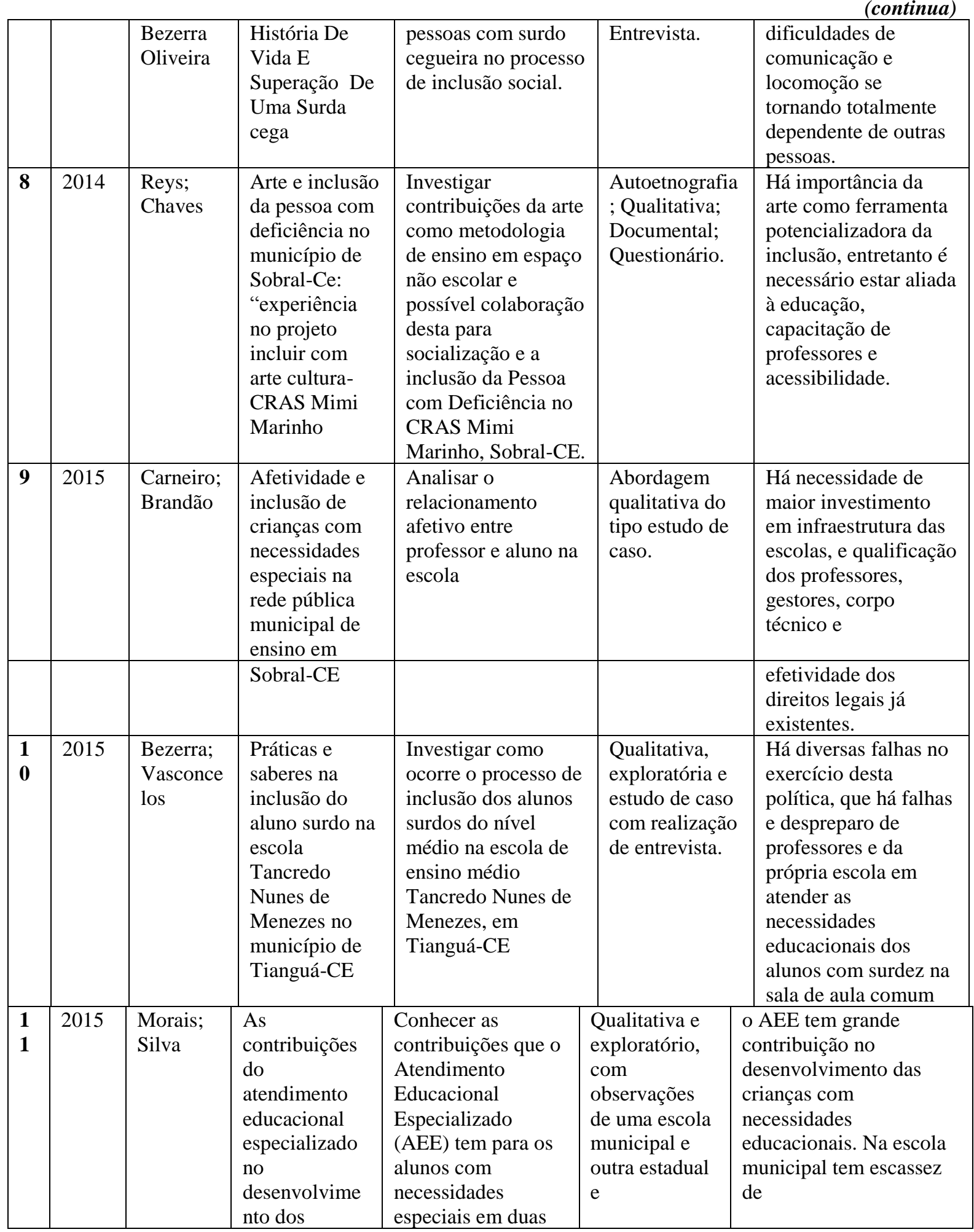


(continua)

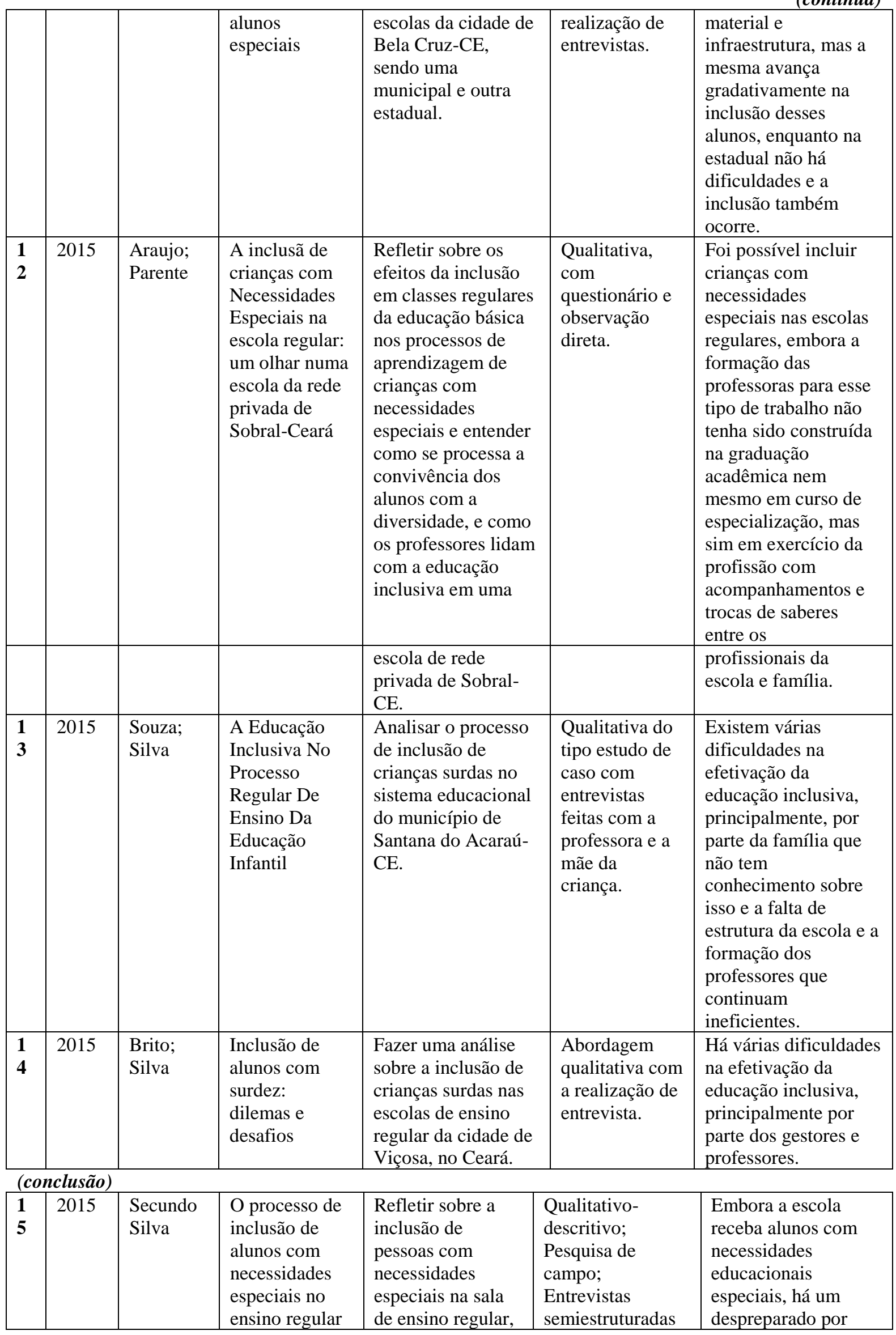




\begin{tabular}{|c|c|c|c|c|c|c|}
\hline & & & & $\begin{array}{l}\text { relatando as } \\
\text { dificuldades } \\
\text { encontradas por } \\
\text { docentes e } \\
\text { discentes na } \\
\text { cidade de Bela } \\
\text { Cruz-CE. }\end{array}$ & & $\begin{array}{l}\text { parte dos professores } \\
\text { e uma infraestrutura } \\
\text { inadequada para } \\
\text { receber esses alunos. }\end{array}$ \\
\hline $\begin{array}{l}1 \\
6\end{array}$ & 2016 & $\begin{array}{l}\text { Rodrigue } \\
\mathrm{s} ; \\
\text { Vieira }\end{array}$ & $\begin{array}{l}\text { A formação do } \\
\text { pedagogo na } \\
\text { atuação com } \\
\text { crianças } \\
\text { autistas: } \\
\text { desafios e } \\
\text { potencialidades }\end{array}$ & $\begin{array}{l}\text { Discutir sobre a } \\
\text { formação do } \\
\text { pedagogo na } \\
\text { atuação com } \\
\text { crianças autistas. }\end{array}$ & $\begin{array}{l}\text { Qualitativa; } \\
\text { Pesquisa de } \\
\text { Campo; } \\
\text { Questionário } \\
\text { aplicado aos } \\
\text { docentes de } \\
\text { autistas em } \\
\text { instituição de } \\
\text { Massapê-Ce }\end{array}$ & $\begin{array}{l}\text { A formação docente } \\
\text { atual nos cursos de } \\
\text { graduação, em } \\
\text { Pedagogia, para atuar } \\
\text { com a Educação } \\
\text { Especial apresenta } \\
\text { fragilidades no } \\
\text { processo. }\end{array}$ \\
\hline $\begin{array}{l}1 \\
7\end{array}$ & 2016 & $\begin{array}{l}\text { Furtado;F } \\
\text { reire }\end{array}$ & $\begin{array}{l}\text { As } \\
\text { contribuições } \\
\text { do atendimento } \\
\text { educacional }\end{array}$ & $\begin{array}{l}\text { Saber a relevância } \\
\text { que o AEE tem na } \\
\text { instituição Centro } \\
\text { de Atendimento }\end{array}$ & $\begin{array}{l}\text { Pesquisa de } \\
\text { campo; } \\
\text { Qualitativa; } \\
\text { Exploratória;Obse } \\
\text { rvações; }\end{array}$ & $\begin{array}{l}\text { Ainda falta muito } \\
\text { para essa modalidade } \\
\text { ser estabelecida } \\
\text { como uma entidade, } \\
\text { que }\end{array}$ \\
\hline $\begin{array}{l}1 \\
7\end{array}$ & & & $\begin{array}{l}\text { especializado- } \\
\text { AEE para o } \\
\text { desenvolvimen } \\
\text { to do aluno } \\
\text { com } \\
\text { deficiência }\end{array}$ & $\begin{array}{l}\text { Educacional } \\
\text { Especializado - } \\
\text { CAEE em } \\
\text { Massapê-CE bem } \\
\text { como conhecer } \\
\text { um pouco sobre a } \\
\text { trajetória da } \\
\text { educação } \\
\text { inclusiva, seus } \\
\text { avanços e } \\
\text { contribuições } \\
\text { positivas ou não } \\
\text { para o } \\
\text { desenvolvimento } \\
\text { pedagógico e o } \\
\text { desenvolvimento } \\
\text { social e afetivo } \\
\text { dos discentes em } \\
\text { questão. }\end{array}$ & $\begin{array}{l}\text { Entrevistas } \\
\text { semiestruturadas. }\end{array}$ & $\begin{array}{l}\text { o AEE é essencial } \\
\text { aos alunos com } \\
\text { deficiências, mas há } \\
\text { uma necessidade de } \\
\text { interligar a escola } \\
\text { regular e o CAEE. }\end{array}$ \\
\hline
\end{tabular}

FONTE: MEDUC (2017)

A análise dos resultados acima expostos se dará em quatro categorias de análise de acordo com os interesses de pesquisa: 1. Autoria e ano de publicação; 2. Percurso metodológico; 3. Eixos abordados; e 4. Objetivo versus desfecho.

Tabela 1: Autoria e Ano de Publicação

\begin{tabular}{llcc}
\hline Ano de Defesa & Identificação & (n=17) & \% \\
\hline 2012 & A1; A2 & 2 & 12 \\
2013 & A3; A4; A5; A6; A7 & 5 & 29 \\
2014 & A8 & 1 & 6 \\
2015 & A9; A10; A11; A12; A13; A14; A15 & 07 & 41 \\
2016 & A16; A17 & 02 & 12
\end{tabular}

Fonte: Dados Primários 
Quanto a autoria os artigos são de dois autores, orientando/orientador, no processo de Trabalho de Conclusão de Curso. Há maiores representações da produção acadêmica nos anos de 2013 e 2015, todavia se evidencia forte decréscimo em 2014, uma produção, aproximando-se dos achados de Rufino et al (2016) realizado no Portal CAPES sobre Estratégias de Ensino e Recursos Pedagógicos na Educação Física o maior quantitativo foram nos anos de 2013 e 2015 e de Oliveira et al (2016) nas bases de dados Lilacs, SciELO, Cochrane, Medline e PubMed sobre A Inclusão de Pessoas Com Necessidades Especiais no Ensino Superior com maior resultado de produção no ano de 2013.

Estes dois recortes temporais estão precedidos da Lei No 12764/12 (BRASIL, 2012) que reconhece e faz valer os direitos das pessoas com Transtorno do Espectro Autista (TEA) bem como da Lei $N^{\circ}$ 13146/15 (BRASIL, 2015), intitulada Lei da Brasileira de Inclusão da Pessoa com Deficiência imputa à todos o cuidado para não discriminação, exclusão e direito à igualdade.

Tabela 2: Percurso Metodológico

\begin{tabular}{llcc}
\hline Abordagem & Identificação & $(\mathbf{n = 1 7 )}$ & \% \\
\hline Qualitativa & A1, A2, A6, A7, A10, A11, A14 & 7 & 41 \\
Não definiram & A3, A4, A5, A8, A9, A12, A13, A15, A16, A17 & 10 & 59 \\
\hline Tipo de Estudo & Identificação & $(\mathbf{n = 1 7 )}$ & $\mathbf{\%}$ \\
\hline Estudo de Caso & A1, A7, A8, A9, A13 & 5 & 29 \\
Rev. Bibliográfica & A3, A6 & 2 & 12 \\
Exploratória & A4, A5, A11 & 3 & 18 \\
Pesq. de Campo & A10, A15, A17 & 3 & 18 \\
Não Classificado & A2, A12, A14, A16 & 4 & 23 \\
\hline Coleta de Dados & Identificação & $(\mathbf{n = 1 7 )}$ & $\mathbf{\%}$ \\
\hline Entrevista & A2; A10; A13; A14; A15 & 5 & 28 \\
Questionário & A4; A5; A12; A13; A16 & 5 & 28 \\
Observações & A12 & 1 & 6 \\
Não especificaram & A1; A7; A8; A9; A11; A17 & 6 & 33 \\
Outros & A3; A6 & 2 & 11 \\
\hline
\end{tabular}

Fonte: Dados Primários

Dentre a abordagem presente nos estudos há destaque para o estudo qualitativo haja vistas que neste tipo de abordagem o cientista é, ao mesmo tempo, o sujeito e o objeto de suas pesquisas, "Ela preocupa-se, portanto, com aspectos da realidade que não podem ser quantificados, centrando-se na compreensão e explicação da dinâmica das relações sociais.” (GERHARDT; SILVEIRA, 2009 p. 32), “[...] é possível desenvolver perguntas e hipóteses antes, durante e depois da coleta e da análise dos dados." (SAMPIERI; COLADO; LÚCIO, 2013). 
Ainda para os estudos nas áreas de Ciências Humanas e Sociais a pesquisa qualitativa é o mais indicado uma vez que permite ao pesquisador contato direto com a realidade, com o fenômeno, podendo correlacionar suas diversas dimensões conseguindo descrever e explicitar melhor os ambientes, os espaços e as formas como as relações se desencadeiam no cotidiano (SAMPIERI; COLADO; LÚCIO, 2013).

Dentre os tipos, destacam-se o estudo de caso, onde o pesquisador tem o mínimo possível de interferência dada à proximidade com o objeto de estudo (RIBEIRO, 2008), “[...] mostrar como de fato algo está ocorrendo, [...].” (CHAER; DINIZ RIBEIRO, 2011, p. 9).

Quanto ao instrumento de coleta de dados, destaca-se o uso do questionário, disposto, geralmente com questões elaboradas pelo pesquisador que permite agilidade na coleta e menos gastos, além de poder deixar o sujeito mais à vontade para as respostas e a entrevista segundo método mais escolhido pelos pesquisadores, pois consegue depreender de forma mais concisa os pontos de vista dos sujeitos sendo possível interpretar, até os elementos não verbais (BAPTISTA; CUNHA, 2007).

Tabela 3: Eixos mais abordados dentro da Educação Especial/Inclusiva

\begin{tabular}{llcc}
\hline Eixo & Identificação & $(\mathbf{n = 1 7})$ & \% \\
\hline Transtorno do Déficit de Atenção e Hiperatividade & A1 A7, A10, A12, & 7 & 4 \\
Inclusão Social e Escolar & A2, A1, A14, A15 & & \\
& A13, A6, A16 & 3 & 17 \\
Formação de Professores & A4 & 1 & 6 \\
NEE & A5 & 1 & 6 \\
Avaliação & A8 & 1 & 6 \\
Metodologia de Ensino & A9 & 1 & 6 \\
Afetividade & A11; A17 & 2 & 12 \\
AEE & &
\end{tabular}

Fonte: Dados Primários

Ainda é motivo de preocupação a inclusão social e escolar dos deficientes. Dentre os estudos que apontam a inclusão, um deles aborda como os deficientes são inclusos ou não no meio social. Ainda que haja expressivo número de revistas que abordem a inclusão, ainda há especificidades que estão aquém de serem debatidas no meio acadêmico científico como bem aponta o estudo de Rufino et al (2016) quanto a inclusão de alunos com deficiência visual em aulas de Educação Física.

De forma semelhante, a formação de professores ocupou lugar de destaque nos resultados do estudo de Oliveira et al (2016) sobre docentes que atuam no ensino superior e formam profissionais para lidar com a inclusão nos espaços escolares. Percebe-se um 
fosso entre o discurso formativo e a realidade da prática de sala de aula quando os profissionais pedagogos adentram o mercado de trabalho assim como o estudo de Espote, Cerralha e Comin (2013) sobre inclusão de surdos identifica como sendo o maior problema a pouca formação dos profissionais professores.

Ainda se encontram ementas e Projetos Pedagógicos de Cursos de Graduação em Pedagogia que abrem pequenos espaços de estudos e de reflexões na sua matriz curricular para o ensino sobre Educação Especial, cabendo esse assunto ser aprofundado nos cursos de Pós-Graduação Lato Sensu, quando na verdade o contato com àquela educação não aguardará a formação à nível de especialista.

Tabela 4: Objetivos versus Desfecho

\begin{tabular}{|l|l|c|c|}
\hline Relação & Identificação & $(\mathbf{n = 1 7 )}$ & \% \\
\hline Positiva & A12; A14 & 1 & 12 \\
\hline Negativa & A1; A2; A3; A4; A5; A6; A7; A8; A9; A10; A11; A13; A15; A16; A17 & 15 & 88 \\
\hline
\end{tabular}

Fonte: Dados Primários

É importante que se identifique o desfecho de uma pesquisa, buscando acompanhar se estes são positivos ou negativos e como isso impacta na situação cotidiana dos sujeitos envolvidos direta ou indiretamente. Neste estudo a prevalência da relação objetivo e desfecho de forma negativa desvela pontos importantes para reflexões e discussões dentro dos espaços de formação de professores.

Figura 1: Síntese do Conhecimento

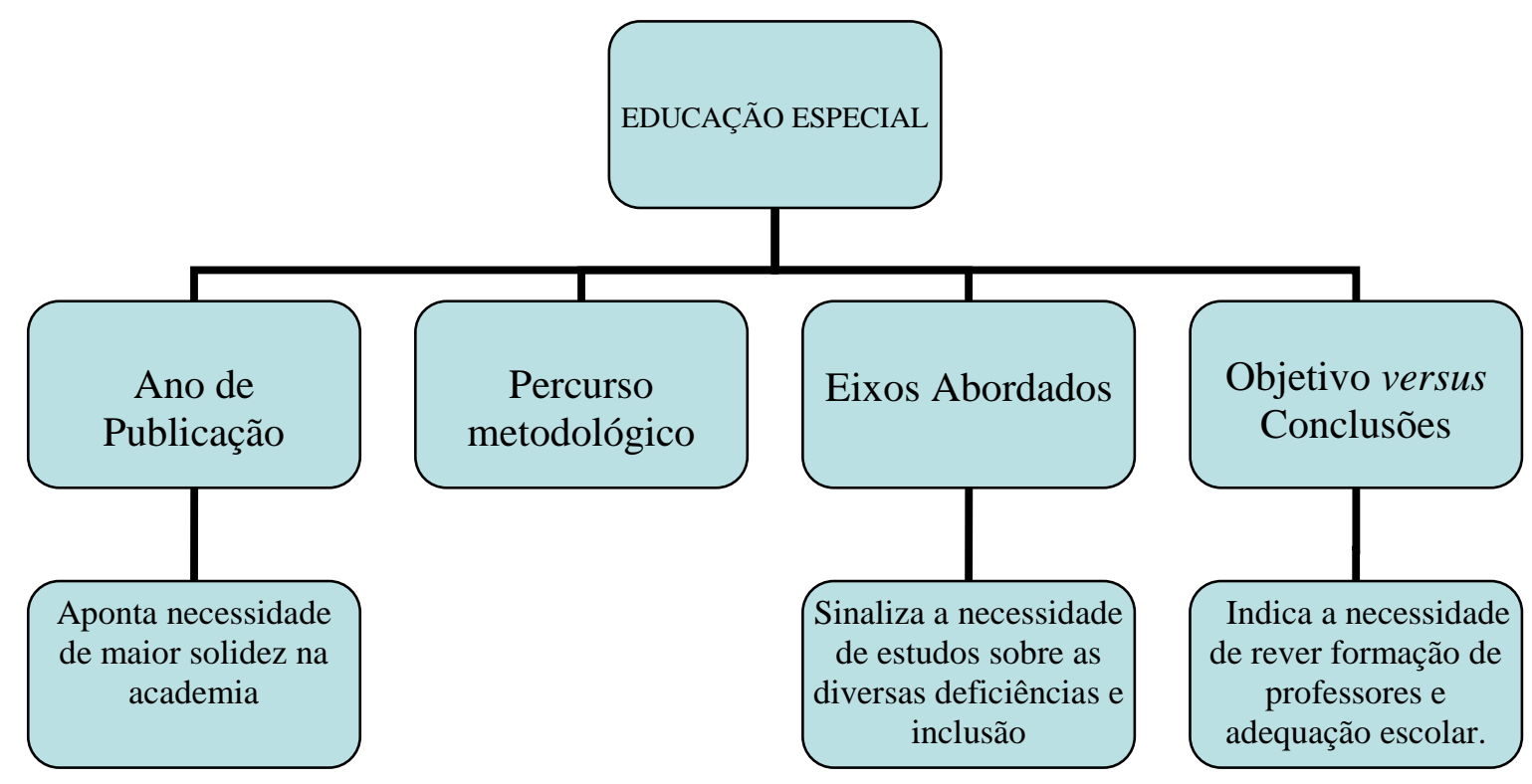

FONTE: Criado a partir de dados da pesquisa (2017) 


\section{Considerações finais}

O estudo realizado e apresentado sobre a Educação Especial permitiu reflexões sobre esse tema tão significante para o meio sócio educacional. O intuito dessa pesquisa foi analisar a produção científica do Curso de Pedagogia da Universidade Estadual Vale do Acaraú sobre a temática Educação Especial. O objetivo dessa pesquisa foi alcançado, pois com os materiais selecionados foi possível fazer essa análise, pois os artigos selecionados ofereceram dados precisos sobre o assunto.

De acordo com as análises dos artigos do MEDUC ficou claro que as crianças com deficiência estão entre "pontos e nós". "Pontos" porque as leis, decretos e declarações voltadas para a Educação Especial ressaltam o que o governo almeja impor na sociedade. "Nós" pelo fato dessa legislação, na prática, não surtir efeitos tão positivos, já que na maioria dos casos analisados, as crianças com deficiências não estão sendo incluídas da maneira correta, mas sim excluídas de maneira velada.

Percebeu-se com essa pesquisa que a formação de profissionais para lidar com esse público ainda é precária e que a sociedade em si ainda é muito preconceituosa. Muitos docentes têm desejo de ajudar, mas desconhecem qual prática pedagógica é a mais viável, já que na graduação não é abordado essa temática com profundidade.

Considerando-se que o ato educativo é pedagógico e ao mesmo tempo político, é preciso elevar a capacidade crítica de todos os profissionais da área educacional de modo que eles percebam que a escola está inserida em contextos de injustiças e de desigualdades que precisam ser modificados. Portanto é imprescindível que o meio sócio educacional aprenda a conviver com as diferenças, respeitando a peculiaridade de cada indivíduo, desatando os "nós" que os excluem e construindo o "nós" que os incluem.

As limitações da pesquisa foram: encontrar artigos recentes do MEDUC sobre o tema em questão, e o fato da proposta do pesquisador não ser essa na totalidade, mas devido às novas regras da Secretária de Educação, foi preciso modificá-la dentro de um intervalo de tempo pequeno. Apesar dessas limitações, foi possível concluir que há uma enorme necessidade de ir além e explorar mais a temática dessa pesquisa, pois a mesma tem grande contribuição para a vida profissional do educador e uma vez que este tenha capacitação para lidar com deficientes, poderá ser o início da mudança que essas crianças necessitam. 
A pesquisa trouxe contribuições gratificantes para a vida profissional do pesquisador, pois conhecendo sobre as leis e as dificuldades encontradas para lidar com essa clientela, a pesquisadora, futura pedagoga, pretende assim modificar suas ações para que possa desatar esses nós e construir o tão esperado nós, já que a sala de aula é um ambiente muito plural e a necessidade de alguém capacitado para lidar com essa clientela é constante e essencial.

\section{REFERÊNCIAS}

BAPTISTA, S. G.; CUNHA, M. B. Estudo de usuários: visão global dos métodos de coleta de dados. Perspect. ciênc. inf. [online], v.12, n.2, p.168-184, 2007

BRASIL. Declaração de Salamanca sobre princípios, políticas e práticas na área das necessidades educativas especiais. Brasília: MEC, 1994. BRASIL. Ministério da Educação.

BRASIL. Constituição da República Federativa do Brasil de 1988. Disponível em: <https://legislacao.planalto.gov.br/legisla/legislacao.nsf/viwTodos/509f2321d97cd2d20325 6b280052245a?OpenDocument\&Highlight=1, constitui\%C3\%A7\%C3\%A3o\&AutoFramed >. Acesso em: 25 jul. 2017.

BRASIL. Casa Civil. Decreto no 3.298, de 20 de Dezembro de 1999. Disponível em: <http://www.planalto.gov.br/ccivil_03/decreto/d3298.htm>. Acesso em: 25 jul. 2017.

BRASIL. Decreto no 3.956, de 8 de Outubro de 2001. Disponível em: <http://www.planalto.gov.br/ccivil_03/decreto/2001/d3956.htm>. Acesso em: 25 jul. 2017.

BRASIL. Decreto no 5.626, de 22 de Dezembro de 2005. Disponível em: <http://www.planalto.gov.br/ccivil_03/_ato2004-2006/2005/decreto/d5626.htm>. Acesso em: 25 jul. 2017.

BRASIL. Decreto no 6.571, de 17 de Setembro de 2008. Disponível em: <http://www.planalto.gov.br/ccivil_03/_ato2007-2010/2008/decreto/d6571.htm>. Acesso em: 25 jul. 2017.

BRASIL. Decreto no 6.949, de 25 de Agosto de 2009. Disponível em: <http://www.planalto.gov.br/ccivil_03/_ato2007-2010/2009/decreto/d6949.htm>. Acesso em 25 jul. 2017.

BRASIL. Decreto $\mathbf{n}^{\mathbf{7}} \mathbf{7 2 . 4 2 5}$, de 3 de Julho de 1973. Disponível em: <http://www2.camara.leg.br/legin/fed/decret/1970-1979/decreto-72425-3-julho-1973420888-publicacaooriginal-1-pe.html>. Acesso em: 25 jul. 2017.

BRASIL. Estatuto da Criança e do Adolescente. Vade Mecum Saraiva. Ed. Saraiva, 2010. 
BRASIL. Lei de Diretrizes e Bases da Educação. LDB 4.024 de dezembro de 1961.

BRASIL. Lei no 10.436, de 24 de Abril de 2002. Disponível em:

<http://www.planalto.gov.br/ccivil_03/leis/2002/110436.htm>. Acesso em: 25 jul. 2017.

BRASIL. Lei n⿳ 12.764, de 27 de dezembro de 2012. Disponível em

<http://www.planalto.gov.br/ccivil_03/_ato2011-2014/2012/lei/112764.htm>. Acesso em: 25 jul. 2017.

BRASIL. Lei no 13.146, de 6 de julho de 2015. Disponível em: <http://www.planalto.gov.br/ccivil_03/_ato2015-2018/2015/lei/113146.htm>. Acesso em: 25 jul. 2017.

BRASIL. Lei no 4.169, de 4 de Dezembro de 1962. Disponível em:

<http://www.planalto.gov.br/ccivil_03/leis/1950-1969/L4169.htm>. Acesso em: 25 jul.

2017.

BRASIL. Lei no 5.692, de 11 de Agosto de 1971. Disponível em:

<http://www.planalto.gov.br/ccivil_03/leis/L5692.htm>. Acesso em: 25 jul. 2017.

BRASIL. Lei $\mathbf{n}^{\mathbf{0}}$ 8.160, de 8 de Janeiro de 1991. Disponível em:

<http://www.planalto.gov.br/ccivil_03/leis/L8160.htm>. Acesso em: 25 jul. 2017.

BRASIL. LDB: Lei de diretrizes e bases da educação nacional: Lei no 9.394, de 20 de dezembro de 1996, que estabelece as diretrizes e bases da educação nacional. - 13. ed. Brasília: Câmara dos Deputados, Edições Câmara, 2016.

BRASIL. Ministério da Educação. Diretrizes nacionais para a educação especial na educação básica/Secretária de Educação Especial - MEC, SEESP, 2001.

BRASIL. Ministério da Educação. Resolução CNE/CEB 4/2010. Diário Oficial da União, Brasília, 14 de julho de 2010, Seção 1, p. 824. Disponível em:

<http://portal.mec.gov.br/dmdocuments/rceb004_10.pdf>. Acesso em: 25 jul. 2017.

BRUNO, M. M. G. Educação infantil: saberes e práticas da inclusão: introdução. 4. ed. Brasília: MEC, Secretaria de Educação Especial,2006.

CAPELLINI, V.L.M.F.; MENDES, E. G. Bases Históricas da Educação Especial no Brasil e a perspectiva da Educação Inclusiva. (texto produzido para a disciplina Educação Especial no Brasil) - mimeo, 2005.

CAMPOS, L. S. Avaliação e reeducação psicomotora e sócio-cognitiva de crianças de classe especial da E. E. P. G. Marechal Floriano. Anais da Mostra de T. G. I. - v. 1, n. ${ }^{\circ} 1$, $1^{\circ}$ Semestre de 1999, p. 12.

CHAER, G.; DINIZ, R. R. P.; RIBEIRO, E. A. A técnica do questionário na pesquisa educacional. In: Evidência, olhares e pesquisas em saberes educacionais. v.7, n.7, p.251266, 2011. Araxá. 
ESPOTE, R.; SERRALHA, C. A.; COMIN, F. S. Inclusão de surdos: revisão integrativa da literatura científica. Psico-USF, Bragança Paulista, v. 18, n. 1, p. 77-88, jan./abr. 2013.

GERHARDT, T. E.; SILVEIRA, D. T. Métodos de pesquisa. 2009.

GUHUR, M. L. P. A Política de inclusão de pessoas com deficiência no ensino regular: demandas da globalização excludente. In: CARVALHO, E. J. G. de; FAUSTINO, R. C. Educação e Diversidade Cultural. Maringá: Eduem, 2012. p. 223-249.

MALHOTRA, N. Pesquisa de marketing: uma orientação aplicada. 4 ed. Porto Alegre; Booman, 2006.

MARFINATI, A. C. Um estudo histórico sobre as práticas psicanalíticas institucionais com crianças autistas no Brasil. Assis, 2012.

MENDES, E. G. Deficiência mental: a construção científica de um conceito e a realidade educacional. 3887 f. (Tese de Doutorado em Psicologia) - Universidade de São Paulo (USP), São Paulo, 1995.

MENDES, K. D. S.; SILVEIRA, R. C. C. P.; GALVÃO, C. M. Revisão integrativa: método de pesquisa para a incorporação de evidências na saúde e na Enfermagem. Texto Contexto Enferm, Florianópolis, v. 17, n. 4, p. 758-64, out-dez, 2008.

OLIVEIRA, R. Q. et al. A inclusão de pessoas com necessidades especiais no ensino superior. Rev. Bras. Ed. Esp., Marília, v. 22, n. 2, p. 299-314, abr./jun. 2016

PÓSTEL, J.; QUÉTEL, C. Historia de la psiquiatría. In J. Póstel \& C. Quétel,Nacimiento de la psiquiatría infantil (destinos de la idiocia, origen de las psicosis)(p. 507525). Cidade do México, México: Fondo de Cultura Económica. 1988.

RIBEIRO, E. A perspectiva da entrevista na investigação qualitativa. In: Evidência, olhares e pesquisas em saberes educacionais. n.4, maio de 2008. Araxá.

ROSSETTO, E.; TURECK, L. T. Z. Refletindo sobre a educação especial. 2005.Disponível em: <http://cac-

php.unioeste.br/projetos/gpps/midia/seminario1/trabalhos/Educacao/eixo1/76ElisabethRos setto.pdf>. Acesso em: 25 fev. 2017.

RUFINO, M. B. et al. Estratégias de ensino e recurso pedagógico nas aulas de Educação Física: uma revisão integrativa. Revista Científica Fagoc Multidisciplinar. v. 1, n. 2, 2016.

UNESCO. Declaração de Salamanca: sobre princípios, políticas e práticas na área das necessidades educativas especiais, 1994 Disponível em:

<http://portal.mec.gov.br/seesp/arquivos/pdf/salamanca.pdf>. Acesso em: 10 mar. 2017.

UNESCO. Declaração Mundial sobre Educação para Todos: satisfação das necessidades básicas de aprendizagem, 1990. Disponível em: 
$<$ http://unesdoc.unesco.org/images/0008/000862/086291por.pdf>. Acesso em: 25 fev. 2017.

\section{Como referenciar este artigo}

NASCIMENTO, Wildiane Gonçalves do et al. Entre pontos e nós: a produção científica sobre Educação especial no curso de pedagogia da UVA-SOBRAL-CE. Revista on line de Política e Gestão Educacional, Araraquara, v. 21, n. esp. 02, p. 1208-1227, nov. 2017. Disponível em: <http://dx.doi.org/10.22633/rpge.v21.n.esp2.2017.10192>. E-ISSN:15199029.

Submetido em: 30/07/2017

Aprovado em: 20/10/2017 